\title{
Persons Placed in Social Protection Institutions as Subjects of Clinical Research by International and Serbian Regulations
}

\author{
Nina Planojević \\ Faculty of Law \\ University of Kragujevac, \\ Kragujevac, Republic of Serbia \\ e-mail: nplanojevic@jura.kg.ac.rs
}

\author{
Dragica Živojinović \\ Faculty of Law \\ University of Kragujevac, \\ Kragujevac, Republic of Serbia \\ e-mail: dzivojinovic@jura.kg.ac.rs
}

\begin{abstract}
Subject of the paper is analysis of the position of persons placed in social protection institutions as subjects of clinical research. In its first part, authors determine who belongs to the category of these subjects and what reasons make them vulnerable, more sensitive than other people in this context. In the second part of the paper, they elaborate efficiency of additional protection forms provided to these subjects by international regulations and regulations of the Republic of Serbia - solutions of which are mutually different. Result of made analysis is a proposal of new, in the authors' opinion most appropriate model of protection of persons in question within clinical researches.
\end{abstract}

Keywords-medical law; clinical research; vulnerable subjects; persons placed in social protection institutions.

\section{INTRODUCTION}

Clinical trials of new medicines in human beings are unavoidable stage of their future safe application; therefore, there is no medicine progress without clinical research or survival of mankind. Although their importance is indisputable, clinical research in human being cannot be performed without its consent [1], because right to autonomy and self-determination regarding body is one of the fundamental human rights. Although consent [2] is the most important measure of human being's protection from possible misuses within clinical research, numerous research scandals all over the world [3] showed that such protection is not sufficient for certain categories of persons. Certain persons for their personal features, social position, living circumstances or for other reasons are more vulnerable and more susceptible to misuses by others; therefore, it is believed that beside consent additional terms guaranteeing their protection have to be fulfilled for their participation in research (minors, pregnant women, refugees, prisoners, etc.). They are named vulnerable subjects [4]; common feature for them is: presumably, mentioned reasons are cause of their diminished capability to protect personal interests, and this is manifested in compromised capability of giving voluntary consent to participation in research [5].

Analysis of one of vulnerable subjects' categories position was selected for the topic of the paper as least elaborated one - persons placed in social protection institutions. Reason for selection of this topic are new regulations of the Republic of Serbia which classify mentioned persons in a separate category, regulating their position in a unique manner, unlike international regulations in the field of clinical research. International regulations categorize many persons placed in different institutions of social protection as vulnerable subjects; however, they are not treated as separate category whose "common denominator" is also a cause of their specific sensitivity and that is exactly their stay in specific conditions of these institutions - on the other hand, this was done within Serbian regulations (for justified reasons). Our first step in going to be to establish who belongs to this category of subjects and what is causing their specific sensitivity and need for additional protection in research. Then, we will analyze measures for their protection foreseen by the most relevant international regulations in this field, as well measures prescribed by Serbian legislator differing than international once. On the basis of the comparison of these solutions, and having in mind also causes of specific sensitivity of this category of participants in research, we will try to identify the most acceptable model of their protection.

\section{Who Belongs to THE CATEgORY OF PERSONS PLACED IN SOCIAL PROTECTION INSTITUTIONS?}

In order to apply measures of additional protection within research over persons placed in social protection institutions, it is primarily necessary to establish who belongs to this category of subjects. Since none of regulations in the field of clinical research we will analyze does contain regulations referring to that, answer to this question has to be sought in laws regulating work and types of social protection institutions in each state individually.

Having these regulations in mind, as in most of the countries, in Serbia following persons can be classified in this group of persons: 1) children with no parents' care living in centers for neglected children; 2) elder, powerless and disabled persons who cannot live without assistance of other persons placed in proper institutions; 3) mentally ill persons placed in adequate institutions, because either their relatives are not able to take care of them or for mandatory medical treatment; 4) in the widest possible sense, here also belong homeless persons and ,children from the street“" occasionally staying in so-called "hangouts" (when it is very cold, or to get meal...) - and for this they are different than other persons from this group staying in institutions continuously, in shorter or longer period of time or even for their life time; 
5) victims of family violence living in so-called «safe houses»; 6) refugees and potential asylum-seekers living in collective accommodation, etc. In our opinion, refugees should be categorized in this group only if they cumulatively fulfill two terms: have refugee status and live in institutions intended to accommodation of refugees. Refugees living in their own or rented accommodation should not be classified to this category since their position is different than other persons living in specific conditions of collective accommodation provided by the state - where exactly is the reason of their vulnerability as further elaboration will show.

\section{REASONS FOR SPECIAL PROTECTION OF PERSONS PLACED IN SOCIAL PROTECTION INSTITUTIONS}

We would classify all mentioned subjects in three groups, according to sort of reasons making them particularly sensitive and make their consent insufficient for participation in clinical research: 1) persons who are not able of living without others care and have no one to take care of them (illness, disability, child age, old age); 2) persons who had to leave their home country for war, political persecution or other dangers for life, physical or psychical integrity (refugees, asylum-seekers, family violence victims); 3) persons left with no property and means for life for other reasons (homeless). Two facts are common for all mentioned subjects. First, they got involuntarily in hard living condition - different than conditions in which other people live. Second, they are not capable to completely take care of themselves but care has to be totally or partly taken by state and society providing them lacking living conditions. Sometimes these lacking conditions are just care and accommodation, provided by the state or other subjects and paid by these persons (accommodation in centers for disabled persons, nurseries, etc.); and sometimes they exactly lack financial means for life and accommodation provided by the state and society (family violence victims, refugees, homeless people ...).

Living situation of mentioned persons is a source of stress and insecurity, as well mixed feelings of gratitude and dependency on the society which takes care of them. If we observe their situation from the prism of consent to participation in clinical research, voluntarism and validity of their consent become questionable for several reasons. First, reasoning capacity of a person living under stress and fear for its survival is partly diminished and consequently also person's capacity to correctly overview its interests and make reasonable decisions [6]. Second, these persons can (by mistake) believe that society or persons employed in these institutions, taking care of them and treat them, expect their consent to participate in a research as form of gratitude and "pay-back" to the society for assistance society provides to them. They can also experience this as form of pressure to give consent. Consent, therefore, ceases to be reflection of their free will, but becomes consequence of diminished reasoning capability due to stress; becomes result of fear that care about them will be worst or even stop if they do not give their consent; and, becomes expression of subjects feeling of (moral) obligation to give consent for gratitude, although that is not expected from them in reality [7].
That is how discrepancy between acceptable motive for consent to participation in research and motive due to which persons placed in social protection institution give their consent. If research is a non-therapeutic one (conducted in healthy people) consent is acceptable if it is motivated by humanity and human wish to contribute to medicine progress regardless of danger research bears against health. If research is a therapeutic one, consent is acceptable even when someone's motive is hope that it will contribute to his healing. Since there is a great probability, as explained, that consent of persons placed in social protection institutions will be motivated by other reasons - it is clear that it is not just a reflection of their true will and, therefore, it is not sufficient prerequisite for their participation in research. Acceptance of such consent would mean exploitation of their severe position; for that reason, it is necessary to prescribe additional terms which have to be fulfilled for their participation in research or to prescribe other measures of their protection from misuses [8] - and this will be object of our observations in the following chapter of the article.

\section{PRotection of PERSONS Placed IN SOCIAL \\ PROTECTION INSTITUTIONS BY INTERNATIONAL AND SERBIAN REGULATIONS}

\section{A. International Regulations}

Only two of several international documents regulating the field of clinical research categorize as vulnerable subjects some of subjects we have classified in that category, and who are usually placed in social protection institutions. That is the International ethical guidelines for biomedical research involving human subjects [9] (hereinafter: the Guidelines); in the comment of its Guideline 13 regulating position of vulnerable subjects, following persons are listed, among others: residents of nursing homes, homeless persons and refugees or displaced persons. Same persons are also mentioned in the point 1.16 of the Guideline for Good Clinical Practice [10] (hereinafter: GCP). Difference between these two regulations is that GCP does not foresee any measures of special protection for these persons as participants of researches.

The Guidelines, however, allow participation of all vulnerable subjects in research - including persons in question here - only if there is a „special justification“ for that and with the fulfillment of several additional terms in comparison to terms related to subjects who are not in the list of vulnerable ones and for whose participation their valid consent is sufficient. These terms are: research cannot be equally well conducted in ,less vulnerable subjects“; research objective is to gain knowledge relevant for the health needs of typical or unique vulnerable subject group; research participants, but also other members of the vulnerable group will be provided with reasonable availability of tested method; expected risk of nontherapeutic research is minimal, with the option of its slight increase with the approval of ethical committee; and, when research is going to be participated by persons who cannot give their consent, consent has to be given by their legally authorized representative (comment to the Guideline 13). 
Highest degree of protection for persons placed in social protection institutions is certainly provided by the first of listed terms which foresees their participation in research only when research cannot be successfully conducted in other persons who are not on the list of vulnerable ones or are in other ways less vulnerable. That means these persons will not participate researches if there is the other subject fulfilling participation criteria who is at the same time not refugee, homeless person, disabled or powerless person, etc. or other subject who is one of mentioned persons but does not reside in adequate institution relying on the assistance of the state and society. Since there are many subjects as such, this term means that situations which will require participation of persons placed in social protection institutions in clinical research will be rare. But, the problem may appear with the situation where there are two subjects suitable for conducting the same trials and one of them is vulnerable because he lives in institution of social protection and the other one is vulnerable for some other reason or several different reasons simultaneously [11]; this situation requires assessment who of them is ,less vulnerable“, and such situation is difficult and disputable and can end harmfully for the person whose position is assessed. Also, it is possible that there will be no ,less vulnerable“ subject (ex. trial has to be conducted in disabled persons whose condition requires accommodation in adequate institution). That means persons placed in a social protection institution can find themselves in a situation where research needs to be conducted in them because there are no ,less vulnerable" subjects or because it is assessed that they are exactly „less vulnerable“ in the concrete situation. If that happens, even cumulative fulfillment of all other terms for protection foreseen by the Guidelines cannot solve the problem that research will be participated by the person accompanied by high probability that his consent will not be reflection of his sincere will but a consequence of inacceptable motives (fear of worst care, stress, gratitude to the society, etc.). Namely, fulfillment of other terms: that research will bring health benefit for the vulnerable group subject represents (not necessarily also for the subject) and that tested therapy will be additionally available; that risk of non-therapeutic research subject participates in is minimal [12] and that subject's legally authorized representative agrees with its participation in the research when that is necessary - does not represent any protection of person placed in social protection institution if subject's consent (or representative's consent) is not expression of his true will. Such person ceases to be subject but becomes an object of the research - and that is inacceptable. Therefore, we think protection provided by the Guidelines to persons placed in social protection institutions is incomplete and insufficient.

\section{B. Serbian Regulations}

According to regulations of the Republic of Serbia contained in the Medicines and Medical Products Act [13] (art. 63, par. 1, point 3), persons placed in social protection institutions cannot participate clinical trials under no terms. This form of protection disables participation of mentioned subjects on the basis of their consent, which we cannot actually consider voluntary and acceptable, for already stated reasons - and that is the good side of it. Bad side of such protection is that it disables participation of mentioned persons in research even when consent is an expression of their true will, not consequence of (wrong) belief that society expects gratitude in the form of "sacrifice for general interest" by exposure of their health to a risk researches bear. Such protection is based on irrefutable presumption that consent of persons placed in social protection institutions is never expression of their real will, and this is a disputable position. That is particularly relevant for therapeutic research where consent can be motivated by hope that research will contribute to healing of the subject. Such protection is also problematic from the aspect that researches can be conducted only in certain categories of persons placed in social protection institutions (ill persons, disabled persons). Ban of their participation actually means also no possibility to conduct clinical research of medicines intended to their illness.

\section{CONCLUDING REMARKS}

Consent is not sufficient term for participation of persons placed in social protection institutions in clinical trials both by international and Serbian regulations. Difference is in a form of additional protection provided to these persons. While Guidelines allows their participation in research with fulfillment of special terms intended to minimize this practice, Serbian law bans their participation. As it can be seen from previous analysis, both forms of protection have certain shortcomings. Protection provided by the Guidelines can lead to situations where these persons participate in research although it is not known is their consent expression of the true will or it was given for other motives - thus, protection is incomplete. Protection foreseen by the Serbian law removes shortcomings of the protection provided by the Guidelines, but has inacceptable results in some situations for what we consider it exaggerating.

Having in mind reasons which make these subjects vulnerable, in our opinion, more acceptable model of protection could be obtained by combination of presented solutions: participation of persons placed in social protection institutions in research should be banned in principle except if research conducting is not possible in other persons for medical reasons. Even then consent is not sufficient until an expert (psychologist) does not verify in the interview with the subject (and its legally authorized representative, if there is one) is given consent an expression of the true will and not given for inacceptable motives.If an expert assesses that consent was not an expression of a true will of the subject he cannot participate the research irrespective how it is important for science and society, because this would be opposite to ethical principle by which interest of the subject is more important than interest of the society.

\section{ACKNOWLEDGMENT}

This work was supported by Ministry of Science and Technological Development of the Republic of Serbia, through the Contact No. 179012. 


\section{REFERENCES}

[1] N. Ivović, „Consent to medical experimental treatments”, Legal Life, vol. 485, no. 9, pp. 339-352, December 2004.

[2] M. G. del Carmen, and S. Joffe, "Informed consent for medical treatment and research: A review", The Oncologist, vol. 10, no. 8, pp. 636-641, September 2005.

[3] T. W. Rice, "The historical, ethical and legal background of humansubjects research", Respiratory care, vol. 53, no. 10, pp. 1325-1329, October 2008.

[4] C. H. Coleman, "Vulnerability as a regulatory category in human subject research", The Journal of Law, Medicine and Ethics, vol. 37, no. 1, pp. 12-18, February 2009.

[5] C. Grady, „Vulnerability in research: Individuals with limited financial and/or social resources", The Journal of Law, Medicine and Ethics, vol. 37, no. 1, pp. 19-27, February 2009.

[6] G. A. Sachs, J. Rhymes, and C.K. Cassel, "Biomedical and behavioral research in nursing homes: guidelines for ethical investigations", Journal of American Geriatrics Society, vol. 41, no. 7, pp. 771-777, Jul 1993.

[7] M. L. Maas, L. S. Kelley, M. Park, and J. P. Specht, "Issues in conducting research in nursing homes", Western Journal of nursing research, vol. 24, no.4, pp. 373-389, Jun 2002.
[8] S. Warma, and D. Wendler, "Research Involving Wards of the State: Protecting Particularly Vulnerable Children", The Journal of Pediatrics, vol. 152, no. 1, pp. 9-14, January 2008.

[9] Council for International Organizations of Medical Sciences (CIOMS), International ethical guidelines for biomedical research involving human subjects. Geneva, Switzerland: World Health Organization, 2002.

[10] International Conference on Harmonization of technical requirements for registration of pharmaceuticals for human use, Guideline for Good Clinical Practice. ICH Topic E 6 (R1) London UK, 1997.

[11] L. W. Moor, and M. Miller, „Initiating research with doubly vulnerable populations", Journal of Advanced Nursing, vol. 30, no. 5, pp.1034-1040, November 1999.

[12] L. M. Kopelman, "Minimal risk as an international ethical standard in research", The Journal of Medicine and Philosophy, vol. 29, no. 3, pp. 351-378, Jun 2004.

[13] National Assembly of the Republic of Serbia, Medicines and Medical Products Act, published in "The Official Gazette of the Republic of Serbia“, no. 30/10, 107/12. 